\title{
The Effects of Teacher Empowerment on Teacher Commitment and Student Achievement
}

\section{Mohammad Aliakbari}

Professor, Department of English, Ilam University, Ilam

\section{Fatemeh Azimi Amoli}

Ph.D. Candidate, Department of English, Ilam University, Ilam, Iran

\author{
Doi:10.5901/mjss.2016.v7n4p649
}

\begin{abstract}
The present study examined the effect of teacher empowerment on teachers' commitment and student achievement. A sample of 356 teachers at Payam-e-Noor University, Ilam branch completed two questionnaires, i.e., School Participant Empowerment Scale (SPES) developed by Short and Rinehart (1992) and Organization Commitment Questionnaire (OCQ) developed by Mowday et al.'s (1979). The results of structural equation modeling indicated the six dimensions of decision making, professional growth, status, self-efficacy, autonomy, and impact played a significant role in teacher commitment and student achievement. Teacher empowerment was found to be important in classroom and instructional decisions that enhance organizational effectiveness and improve student performance. These outcomes may be beneficial for policy-makers in directing teachers to a high level of competency, high status and self-esteem and help them to achieve professional growth.
\end{abstract}

Keywords: Teacher Empowerment, Teacher Commitment, Student Achievement

\section{Introduction}

It was not until late 1980s when teacher empowerment came to be viewed as a significant school organizational concern. Maeroff (1988) and Sykes (1990) argued that teacher empowerment is a critical issue that is conducive to schools' efficiency. The focus has been on teachers to have more opportunity to participate in school level decision-making and to utilize greater professional judgment in curriculum and instructional issues.

Generally, teacher empowerment is thought to improve student learning by fostering teaching quality. Still, teacher empowerment is affected by factors like the nature of teaching, the features of teaching as a profession, teacher background knowledge, school organizational features, and its environmental context. According to Marks and Louis (1997), teacher empowerment is an essential condition for enhancing students' academic performance.

According to Marks and Louis (1997), the effects of teacher empowerment on their job satisfaction, self-efficacy, and morale have been examined. Yet, little research has been carried out to display its effects as an expanded commitment to teaching and students. The relationship between empowered and committed teachers instead of those who are less empowered has not been well examined.

Edmonds (1979) stated a large body of research has been performed on potential environmental characteristics that may enhance teacher empowerment. Research has indicated high expectations for student learning, and basic skills as the key environmental characteristics of effective schools. Furthermore, Elmore (1990) suggested transforming school structure, work conditions, and decision-making processes in school organizations as strategies to improve teaching.

Dee et al. (2003) investigated the psychological effects of teacher empowerment on teacher commitment by teacher team participation. Teacher commitment may vary according to school organization, teaching itself, and student school life.

Firestone and Pennell (1993) pointed out that teacher commitment needs to be examined precisely by placing it within student dimensions. This study focused on teacher commitment within the instructional activities of teachers. Teacher commitment to teaching was studied with the expectation that it can contribute to our understanding of student learning. The results showed that this did not make any contribution to student achievement.

\subsection{Teacher Empowerment}

Definitions of teacher empowerment vary depending on various perspectives. However, recent research has increasingly 
approached it as a multidimensional construct. Marks and Louis (1997) maintained that empowerment can be fairly consistently classified into technical-operational and organizational-strategic domains after measuring teacher empowerment through school activities and management, students' school experiences, teachers' work life, and control over classroom instruction.

Park (1998) has defined teacher empowerment based on the three dimensions of control over content, control over methods, and potential effect on school policy. These multi-dimensional studies have assumed that teacher empowerment is defined as teacher participation in decision making. On the other hand, teachers may like applying affect in some domains but not in others. In school decisions where teachers have no experience, they like to preserve a 'zone of indifference', assuming that such decisions should be made by others. However, this does not mean that some teachers intend to be empowered but others do not or that they seek to be empowered in some areas but not in others. Instead, this means that teacher empowerment involves more than participation in decision making.

\subsection{Teacher Commitment}

According to Park (1998), commitment has been identified in various methods. Commitment has a significant implication for teachers. In turn, teacher commitment has been comprehensively defined by placing it within larger dimensions such as organization, occupation, and students (Firestone \& Pennell, 1993) and operationalized as a global concept representing the extent of individual effort (Rowan, 1990b). In general, committed teachers are expected to believe strongly in the goals or purposes associated with teaching as an object, be willing to exert considerable effort in its pursuit, and possess a desire to remain involved with it (Firestone, 1990).

Rowan, (1990b), and Firestone and Pennell (1993) stated that teachers' commitment varies according to the purposes they are committed to. That is, teachers can be committed to teaching itself, to their school organizations, or to their students collectively or individually. Teacher commitment to a school has been displayed by the teachers trying to get involved in matters related to their schools and commitment to students has been represented by the extent to which teachers discuss students' work with them. Lee and Smith (1996) found that students attain more when their teachers take collective responsibility for students' learning. Still, other researchers have argued that the levels of student achievement influence teachers' commitment. When levels of student learning are high, teachers are more willing to embrace responsibility for the efficacy of teaching (Firestone \& Rosenblum, 1988; LeCompte \& Dworkin, 1991).

\section{Significance of the Study}

The main purpose of this study is to examine the effects of teacher empowerment on teacher commitment and student achievement. For this purpose, the concept of teacher empowerment is considered from theoretical views of university organizations. Short and Rinehart (1992) identified teacher empowerment as six features containing (a) decision making; (b) professional growth; (c) status; (d) self-efficacy; (e) autonomy; and (f) impact. Teacher empowerment is more than just teachers' participation in decision making and is directly related to student achievement. This study seeks to provide a better understanding of teacher empowerment by examining its effects on teacher commitment to teaching practices as well as student achievement. In addition, this study investigates the relationships between teacher commitment and student achievement, taking into account teacher empowerment as a mediator.

\section{Statement of the Problem}

The relationship between teacher empowerment, teacher commitment and student achievement has been in general very elusive. In addition, the results from previous research have been contradictory and inconsistent. Many studies have been conducted regarding the involvement of teachers in reform efforts providing evidence of positive results; however, there is no research into the direct relationship between teacher empowerment, teacher commitment and students' academic consequences. Sweetland and Hoy (2000) reported mixed teachers' perceptions of empowerment largely because of the variety and discrepancies in the definition of this notion. Defining teacher empowerment and studying its relationship to student achievement are difficult to accomplish. However, Park (2003) stated that the effects of teacher empowerment on teachers' practice and students' learning need to be evaluated. Studies of the effects of teacher empowerment on students' achievement may overlook the potential effects on teachers' practice. In order to better understand teacher empowerment, its influences on teachers' teaching and students' learning need to be examined. 


\section{Research Questions}

Three major research questions were posed to investigate the effects of teacher empowerment on teachers and students in this study.

Q1: Does teacher empowerment have any impacts on teacher commitment regarding its six features including decision making; professional growth; status; self-efficacy; autonomy; and impact?

Q2: Does teacher empowerment have any impacts on student achievement due to its six features?

\section{Methodology}

\subsection{Participants}

Table 1 indicates the descriptive statistics of participants. Teachers at Payam-e-noor University in three cities in Iran, namely, llam, Tehran and Mazandaran were participants of this research. They were selected randomly. The sample consisted of 356 (145 male and 221 female) EFL teachers. About forty percent were male; and more than half ( 60 percent) were female. More than half of the selected sample was aged between 30-35, and about 35\% between 35-50. Almost fifty teachers had 6-8 years of teaching experience, 36 percent had 4-6 years of experience and the rest had taught English for about 10 years.

Table 1. Frequencies of Teachers' Demographic Data $(N=365)$

\begin{tabular}{lccc}
\hline & & Percent & $F$ \\
\hline \multirow{2}{*}{ Gender } & Male & 39.7 & 145 \\
& Female & 60.3 & 220 \\
\hline \multirow{3}{*}{ Age } & $25-30$ & 13.4 & 49 \\
& $30-35$ & 53.3 & 195 \\
& $35-40$ & 22.7 & 83 \\
Teaching experience & $40-45$ & 5.7 & 21 \\
& $45-50$ & 4.9 & 18 \\
\hline
\end{tabular}

\subsection{Instruments of the study}

A questionnaire measuring teacher commitment and teacher empowerment was mailed to EFL teachers of Payam-e-noor in Iran. The respondents were asked to answer a range of questions about their feelings of empowerment, their commitment and profession in the University.

School Participant Empowerment Scale (SPES) was developed by Short and Rinehart (1992) to evaluate school participants' empowerment. The 38-question SPES instrument not only supplies a measure of teacher empowerment, but also assesses six features including teacher empowerment, decision making, professional growth, status, self-efficacy, autonomy and impact. Decision making refers to the teachers' collective attempts in making meaningful decisions that directly influence their work such as "I make decisions about the implementation of new programs in the University". Professional growth refers to teachers' perceptions that they are involved in opportunities to grow as a professional and participate in learning like "I am treated as a professional". Status is the sense of teachers' esteem that is realized by stakeholders through respect and admiration such as "I believe that I have earned respect" Self-efficacy is teachers' feelings that they have the skills and knowledge necessary to be successful educators like "I believe that I am empowering students". Autonomy is based on one's freedom to make decisions that control aspects of the working condition such as "I have the freedom to make decisions on what is taught" and impact refers to the belief that one has significant influence over consequences at work like "I believe that I have an impact". Then, the overall scale was calculated the reliability of 0.96 and the same reliability level of alpha was found in the current study.

Organization Commitment Questionnaire (OCQ): Organizational commitment was assessed through Mowday et al.'s (1979). This survey was called Organizational Commitment Questionnaire (OCQ). The items of this instrument were 15 items which assess measures affective rather than normative or continuance commitment by asking the respondents to refer to their identification in an institution. The reliability of OCQ was displayed to be 0.87 . 


\section{Data Analysis}

In order to analyze the data, the researchers used Lizrel 8.7 to investigate the model by SEM (structural equation modeling) analyses. In the first phase, an exploratory factor analysis was run to determine the number of factors of questionnaire. We conducted Kaiser-Meyer-Olkin Measure of Sampling Adequacy (KMO) and Bartlett's Test to validate the relationship between observed and latent variables. To investigate the appropriateness of the hypothetical models, goodness of fit indices were used. Therefore, Root Mean Square Error (RMSEA), the comparative fit index (CFI), the Tucker-Lewis index also known as the non-normed fit index (TLI) or (NNFI) (Bentler \& Bonett, 1980), the normed fit index (NFI) and the relative fit index (RFI) showed an appropriate fit.

\section{Results and Discussion}

Prior to data analysis, we had to know whether the data have been normally distributed among the participants or not, which is regarded as one of the assumptions for performing parametric or non-parametric test. Therefore, One-Sample Kolmogorov-Smirnov test was used to check whether the data have been normally distributed or not. As it is evident from Table 2, the level of significance is less than 0.05 indicating that data do not enjoy one of the assumptions of normality. Therefore, it was legitimized to resort to appropriate non-parametric statistics in an attempt to analyze the data concerning the research questions.

Table 2. One-Sample Kolmogorov-Smirnov test for checking the normality assumptions

\begin{tabular}{lcccc}
\hline & N & Mean & SD & Sig. \\
\hline Decision-making & 365 & 2.92 & 1.298 & 0.000 \\
Professional growth & 365 & 2.79 & 1.187 & 0.014 \\
Status & 365 & 2.94 & 1.341 & 0.002 \\
Self-efficacy & 365 & 2.92 & 1.252 & 0.007 \\
Autonomy & 365 & 2.83 & 1.308 & 0.000 \\
Impact & 365 & 2.84 & 1.288 & 0.001 \\
Commitment & 365 & 3.58 & 1.589 & 0.002 \\
\hline
\end{tabular}

As Table 3 indicated, Spearman correlation pointed out the effectiveness of teacher empowerment on teacher commitment with its six features ( $p>0: 05)$. Tables 3 and 4 display the results of descriptive statistics for six variables of teachers' empowerment and the correlation between teachers' commitment and the variables of teachers' empowerment. The outcomes pointed out all subcategories in teacher empowerment were considerably $(P=.000)$ correlated with commitment (ranging from 0.47 to 0.52 ). If teachers figure out their commitment is more toward the teacher empowerment elements, they can move more toward teacher professional development.

Table 3. Spearman correlation for teachers' commitment and six dimensions of teachers' empowerment

\begin{tabular}{llccc}
\hline & Variable & Spearman's Correlation Coefficient & N & Sig. \\
\hline \multirow{4}{*}{ Commitment } & Decision - making & 0.477 & 365 & 0.00 \\
& Professional growth & 0.530 & 365 & 0.00 \\
& Status & 0.470 & 365 & 0.00 \\
& Self-efficacy & 0.526 & 365 & 0.00 \\
& Autonomy & 0.527 & 365 & 0.00 \\
& Impact & 0.505 & 365 & 0.00 \\
\hline
\end{tabular}

Furthermore, in order to see whether teachers' empowerment has any effects on students' achievement, another Spearman correlation analysis was run for analyzing the data related to teachers' commitment and students' achievement. The results of data analysis can be observed in Table 4. As it is evident, there is a positive and significant correlation between teachers' empowerment and students' achievement $(r=0.47 ; \mathrm{P}=0.000)$. 
Table 4. Spearman correlation for teachers' commitment and students' achievement

\begin{tabular}{ccc}
\hline & & Student achievement \\
\hline Empowerment & Spearman's Correlation Coefficient & 0.477 \\
& Sig & 0.000 \\
& $N$ & 365 \\
\hline
\end{tabular}

\section{Exploratory Factor Analysis}

Reducing the number of variables and identifying their internal structure can be effective in analyzing the data more accurately and achieving research results. Exploratory factor analysis is a method that attempts to explore the underlying variables or factors in order to explain the pattern of correlations between the intended variables. This section seeks to investigate the correlation between the variables under investigation in this research. Using exploratory factor analysis, we were able to identify latent variables, which might contribute to explaining the changes in variables, and to define their interactions with each other and other variables in terms of assumptions.

Table 5. Exploratory factor analysis and validity and reliability of the questionnaire

\begin{tabular}{|c|c|c|c|}
\hline Factors & Questions & Factor Loading & Cronbach \\
\hline \multirow{5}{*}{ Decision - making } & Q1 & 0.846 & \multirow{5}{*}{.930} \\
\hline & Q2 & 0.805 & \\
\hline & Q3 & 0.852 & \\
\hline & Q4 & 0.765 & \\
\hline & Q5 & 0.869 & \\
\hline \multirow{9}{*}{ Professional Growth } & Q6 & 0.791 & \multirow{9}{*}{.936} \\
\hline & Q7 & 0.802 & \\
\hline & Q8 & 0.796 & \\
\hline & Q9 & 0.756 & \\
\hline & Q10 & 0.720 & \\
\hline & Q11 & 0.756 & \\
\hline & Q12 & 0.750 & \\
\hline & Q13 & 0.766 & \\
\hline & Q14 & 0.706 & \\
\hline \multirow{5}{*}{ Status } & Q15 & 0.822 & \multirow{5}{*}{.881} \\
\hline & Q16 & 0.784 & \\
\hline & Q17 & 0.818 & \\
\hline & Q18 & 0.869 & \\
\hline & Q19 & 0.822 & \\
\hline \multirow{9}{*}{ Self-efficacy } & Q20 & 0.772 & \multirow{9}{*}{.935} \\
\hline & Q21 & 0.849 & \\
\hline & Q22 & 0.783 & \\
\hline & Q23 & 0.853 & \\
\hline & Q24 & 0.822 & \\
\hline & Q25 & 0.819 & \\
\hline & Q26 & 0.765 & \\
\hline & Q27 & 0.658 & \\
\hline & Q28 & 0.743 & \\
\hline \multirow{4}{*}{ Autonomy } & Q29 & 0.772 & \multirow{4}{*}{.846} \\
\hline & Q30 & 0.840 & \\
\hline & Q31 & 0.844 & \\
\hline & Q32 & 0.867 & \\
\hline \multirow{6}{*}{ Impact } & Q33 & 0.815 & \multirow{6}{*}{.916} \\
\hline & Q34 & 0.784 & \\
\hline & Q35 & 0.853 & \\
\hline & Q36 & 0.806 & \\
\hline & Q37 & 0.800 & \\
\hline & Q38 & 0.843 & \\
\hline
\end{tabular}


The results of KMO-Bartlett test indicate that conducting factor analysis on the data structure is acceptable. The KMO statistic, which has a value more than 0.5 , indicates sampling adequacy and the confidence level of zero for the Bartlett's test, which in turn represents the suitability of factor model.

\section{Structural Model of Research (Evaluation of the Research Model)}

Structural equation model in the standard estimation state is discussed, but it should first be noted that researchers cannot neglect the multivariate data distribution and its normality; otherwise it might lead to wrong conclusions. Such a situation is due to the fact that the most common method of estimation of parameters and their standard errors, namely the maximum likelihood, is based upon assumptions of multivariate normality. In the present study, the multivariate normality assumption has not been established.

Figure 1 and Table 6; display the impacts of the independent variables on the dependent variables. As the results demonstrate, except Status, other elements of teacher empowerment receive a 19, 34, 21, and 15 percent impact on the commitment, respectively. While all strength elements of teacher empowerment include 18, 26, 24, 21, and 17 percent impact on the empowerment, respectively which represent a direct and positive relationship.

Table 6. Investigating the hypotheses using structural equations model

\begin{tabular}{llccc}
\hline & Variables & Amount of Efficiency & Sig & Result \\
\hline Commitment & Decision - making & 0.196 & 0.003 & Accept \\
& Professional growth & 0.345 & 0.000 & Accept \\
& Status & 0.047 & 0.489 & Reject \\
& Self - efficacy & 0.217 & 0.002 & Accept \\
& Autonomy & 0.153 & 0.015 & Accept \\
Empowerment & Decision - making & 0.188 & 0.000 & Accept \\
& Professional growth & 0.265 & 0.000 & Accept \\
& Status & 0.246 & 0.000 & Accept \\
& Self - efficacy & 0.216 & 0.000 & Accept \\
& Autonomy & 0.171 & 0.000 & Accept \\
\hline
\end{tabular}

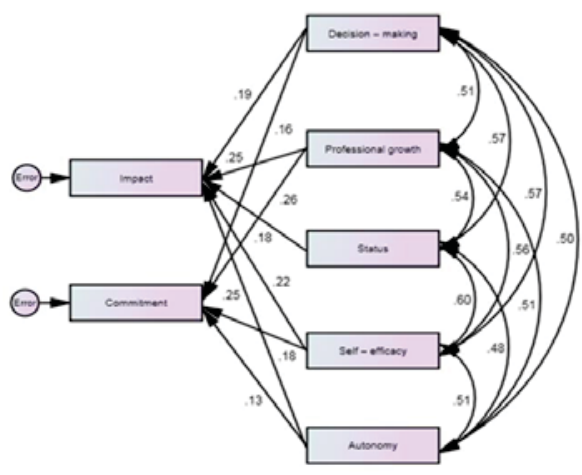

Figure 1. Structural equations model in the standard estimation state

Indicators related to the fitness of the model presented in Table 7 are used in this paper in order to evaluate the appropriateness of the model.

Table 7. Indices related to fitness of structural equations model

\begin{tabular}{llcl}
\hline Index & Acceptable Index & Amount & Result \\
\hline Normal chi-Square & $\left(\mathbf{x}^{2} / \mathbf{d f}\right)<5$ & 0.243 & Accept \\
Root Mean Squared Error of Approximation & RMSEA $<0.05$ & 0.000 & Accept
\end{tabular}




\begin{tabular}{lccc} 
Root Mean Squared Residual & RMR $\geq 0$ & 0.009 & Accept \\
Goodness-of-Fit Index & GFI $>0.9$ & 1 & Accept \\
Adjusted Goodness-of-Fit Index & $\mathrm{AGFI}>0.85$ & 0.995 & Accept \\
Normal Fit Index or Bentler-Bonett Index & $\mathrm{NFI}>0.90$ & 1 & Accept \\
Comparative Fit Index & $\mathrm{CFI}>0.90$ & 1 & Accept \\
Incremental Fit Index & $\mathrm{IFI}>0.90$ & 1 & Accept \\
\hline
\end{tabular}

Estimation results (model fitness) suggest the suitability of indicators, which represents the high fitness of the model.

\section{Discussion}

The findings due to variables either are congruent with previous studies or not. According to Wall and Rinehart (1998), status, self-efficacy, impact, professional growth, autonomy and decision-making were in dipping sequence. The current study represented the same consequences. These explorations display that teachers feel freighted are effective in their job.

Correlation analysis was used to analyze the dimensions of teacher empowerment that affect teacher commitment among the teachers teaching English in an Iranian EFL context. The outcomes of the current study pointed out all six dimensions for teachers' commitment including decision making; professional growth; status; self-efficacy; autonomy; and impact are significantly related to teachers' empowerment. In addition, the other consequences displayed that professional growth, self-efficacy and status predicted organizational commitment which is agreement with Wu and Short (1996). Furthermore, the other outcomes indicated that professional growth, self-efficacy and status forecasted organizational commitment (Porter, Lawler, \& Hackman, 1975).

The effect on teacher commitment seems to be similar to that on teacher efficacy or on teacher empowerment in previous studies (Rowan, Raudenbush, \& Kang, 1991; Gamoran, Porter, \& Gahng, 1994).

Regarding the effect of teacher empowerment on student achievement, the results indicated that teacher empowerment directly impacted on student achievement in Iranian EFL context. The results of the present study can support the findings of prior studies that the dimensions of teacher empowerment had varied impacts on student subject matter achievement (Archbald \& Porter, 1994; Gamoran, Porter, \& Gahng, 1994; Rowan, Raudenbush, \& Kang, 1991). Instead, the findings of this study were incongruent with the studies that reported no effects of teacher empowerment on student achievement (Marks \& Louis, 1997; Park, 1998). Overall, this conclusion is likely to emphasize the efforts to improve student achievement by empowering teachers.

As Gibson and Dembo (1984) have stressed, in educational settings, teachers believe that they can make a difference with their students. The importance of self-efficacy can be described by Bandura (1977). He stated teachers can represent more organizational behaviors where they report higher levels of self-efficacy. Furthermore, teachers have high prospects of themselves to carry out impressively and are entrusted to their job.

As the role of status is related, our consequences display that teachers with high status are more entrusted to the organization. Taking professional growth into consideration, as Boglera and Somech (2004) stated, when a person works in an upbringing atmosphere in order to enhance his professional development, may affect on his sense of responsibility to the organization and the job.

Finally, regarding participation in decision-making, according to Koopman and Wierdsma (1998), decision-making is the final stage which the employees appointed.

\section{Conclusions and Implications}

This research took into account the relationships of teacher empowerment to teacher commitment and student achievement. The main objective was to help understand the relationships of the variables of teacher empowerment and their effect on teacher commitment and student achievement. The results of the present study indicated that the six dimensions of decision making, professional growth, status, self-efficacy, autonomy, and impact which constitute teacher empowerment played a significant role in teacher commitment. Teacher commitment was based on the bureaucratic, professional, and loose coupling perspectives of school organizations (Gamoran, Porter, \& Gahng, 1994; Park, 1998). The three distinctive perspectives provided the contextual conditions for teachers. Overall, the findings of this study tested the hypothesis that teachers who taught in the university with favorable environments would be more empowered and that they, as empowered teachers, would be more likely to be committed to instruction and have a positive influence on students' achievement. 
Given that the six dimensions of the empowerment measure significantly affected teachers' commitment to teaching, it can support an earlier finding that a sense of empowerment increased a teacher's job satisfaction, professional community, and commitment to teaching (Marks \& Louis, 1997). Put differently, a teachers' involvement in the decision making process may detract teachers' energy and time away from teaching. Taken together, these findings indicate that a teachers' sense of empowerment positively affected teacher commitment.

Furthermore, this study examined the relationship between teacher empowerment and student achievement. The findings of prior research on the relationship between teacher empowerment and student achievement were inconsistent. While some studies found a positive correlation, others showed no evidence of a relationship. Generally, the research results showed that perceptions of teacher empowerment; were related to student achievement but the effects varied across a wide range of teacher empowerment dimensions (Gamoran, Porter, \& Gahng, 1994; Park, 1998; Sweetland \& Hoy, 2000). For example, teacher empowerment was found be important in classroom and instructional decisions that enhance organizational effectiveness and improve student performance.

The results of this study indicated that teacher empowerment directly affected student achievement in English language learning. This finding is in congruence with the findings of Gamoran, Porter, and Gahng (1994). The results also supported the professional perspective which assumes positive effects of teacher empowerment on student achievement. Altogether, it is plausible to say that the findings of this study supported the notion that teacher empowerment and student achievement is loosely related.

One of the significant support of the present research is emphasized on the effect of six teacher empowerment characteristics on the outcomes of organizational commitment among the Payam-e-noor Universities in Iranian EFL context. These results can be fruitful to organizations.

All of the teacher empowerment features can be used by university managers to enhance teachers' commitment to the university. Also, it is necessary for policy-makers in different universities to create an appropriate atmosphere to work to direct teachers to a high level of competency, high status and self-esteem. They also require to take into consideration the feelings and perceptions of instructors about the university, and their desire to achieve opportunities for professional growth. Thus, policy-makers in the universities should take into account the role of teachers in making decision about teaching and other variables which may play a role in university promotion.

As far as the implications of the results of the present study outside the university are concerned, policy-makers in different organizations related to training should consider the role of organizational commitment as important. Thus, the Ministry of Science, Research and Technology as the primary decision-making center, and its operational units should foster teachers to workshops to direct them toward teacher professional development, autonomy, status and self-efficacy. It is hypothesized that experienced teachers move toward professional development and are able to get their aims. It is assumed that once the teachers experience greater opportunities for professional growth and acquires greater trust in their ability to achieve high-order goals (i.e., greater self-efficacy), their status will improve as well. As a result, teachers may feel empowered at university when they participate in shared decision-making with the university.

\section{References}

Archbald, D. A., \& Porter. A. C. (1994).Curriculum control and teachers' perceptions of autonomy and satisfaction Educational Evaluation and Policy Analysis, 16(1), 21-39.

Baker, D. K. (2000). An Examination of the Relationship between Employee Empowerment and Organizational Commitment. Unpublished doctoral dissertation. The University of lowa.

Bandura, A. (1977). Social Learning Theory. Englewood Cliffs, N.J.: Prentice-Hall.

Bentler, P.M., \& Bonett, D.G. (1980). Significance tests and goodness of fit in the analysis of covariance structures. Psychological Bulletin, 88, 588-606.

Boglera, R \& Somech, A. (2004). Influence of Teacher Empowerment on teachers' Organizational Commitment, Professional Commitment and Organizational Citizenship Behavior in Schools, Teaching and Teacher Education. 20, 277-289

Dee, J. R., A. B. Henkin, \& L. Duemer. (2003). Structural antecedents and psychological correlates of teacher empowerment. The Journal of Educational Administration.

Edmonds, R. (1979). Effective schools for the urban poor. Educational Leadership, 34(1), 15-24.

Elmore R.F., \& Associates. (1990). Restructuring Schools: The Next Generation of Educational Reform. San Francisco, CA: JosseyBass.

Firestone, W. A., \& J. R. Pennell. (1993). Teacher commitment, working conditions, and differential incentive policies. Review of Educational Research, 63 (4), 489-525.

Firestone, W. A., \& S. Rosenblum. (1988). Building commitment in urban high schools. Educational Evaluation and Policy Analysis, 10 (4), 285-299.

Gamoran, A., Porter, A. C. \& Gahng. T. J. (1994). Teacher empowerment: a policy in search of theory and evidence. Center on 
Organization and Restructuring of Schools, WI: Madison. (ED 372032).

Gibson, S., \& Dembo, M. (1984). Teacher efficacy: A construct validation. Journal of Educational Psychology, 76 (4), 569-582.

Koopman, P. L., \& Wierdsma, A. F. M. (1998). Participative management. In P. J. D. Doentu, H. Thierry, \& C. J. de-Wolf (Eds.), Personnel psychology: Handbook of work and organizational psychology, Vol. 3. (pp. 297-324)Hove, UK: Psychology Press/Erlbaum.

LeCompte, M. D., \& A. G. Dworkin. (1991). Giving Up on School: Student Dropouts and Teacher Burnouts. Newbury Park, CA: Corwin.

Lee, V. E., \& J. B. Smith. (1996). Collective responsibility for learning and its effects on gains in achievement for early secondary students. American Journal of Education. 70, 128-150.

Maeroff, G. I. (1988). The Empowerment of Teachers: Overcoming the Crisis of confidence.

New York, NY: Teachers College Press

Marks, H. M. \& K. S. Louis. (1997). Does teacher empowerment affect the classroom? The implications of teacher empowerment for instructional practice and student academic performance. Educational Evaluation and Policy Analysis, 19 (3), 245-275.

Mowday, R. T., Steers, R.M., \& Porter, L. W. (1979). The Measurement of Organizational Commitment. Journal of Vocational Behavior, $14,224-227$.

Park, B. J. (1998). Teacher Empowerment and Its Effects on Teachers' Lives and Student Achievement in U.S. High Schools. Unpublished doctoral dissertation. The University of Wisconsin, Madison.

Park, B. J. (1998). Teacher Empowerment and Its Effects on Teachers' Lives and Student Achievement in U.S. High Schools. Unpublished doctoral dissertation. The University of Wisconsin, Madison.

Pett MA, Lackey NR, Sullivan JJ. Making Sense of Factor Analysis: The use of factor analysis for instrument development in health care research. California: Sage Publications Inc; 2003.

Porter, L. W., E. E. Lawler, \& J. R. Hackman. (1975). Behavior in Organizations. New York: McGraw-Hill Inc.

Rowan, B. (1990b). Commitment and control: Alternative strategies for the organizational design of school. Review of Research in Education, 16, 353-389.

Rowan, B., S. W. Raudenbush, \& S. J. Kang. (1991). Organizational design in high schools: A multilevel analysis. American Journal of Education, 99, 238-266.

Royse, D., Thyer, B. A., Padgett, D. K., \& Logan, T. K. (2006). Program evaluation: An introduction (4th ed.). Belmont, CA: Thomson.

Short, P. M., \& J. S. Rinehart. (1992). School participant empowerment scale: Assessment of level of empowerment within the school environment. Educational and Psychological Measurement. 52(4), 951-960.

Sweetland, S. R. \& W. K. Hoy. (2000). School characteristics and educational outcomes: Toward an organizational model of student achievement in middle schools. Educational Administration Quarterly. 36(5), 703-730.

Wu, V. \& Short, P. (1996). The relationship of empowerment to teacher job commitment and job satisfaction. Journal of Instruction Psychology, 23,85. 